\title{
Penyuluhan pemanfaatan feses sapi sebagai briket bahan bakar alternatif
}

\author{
Purwanta $^{1}$, Sarti Patontongan ${ }^{2}$, Nuraeni $^{3}$ \\ ${ }^{1}$ Politeknik Pembangunan Pertanian (Polbangtan) Manokwari, Papua Barat \\ ${ }^{2}$ Penyuluh Pertanian Kabupaten Tana Toraja, Sulawesi Selatan \\ ${ }^{3}$ Politeknik Pembangunan Pertanian (Polbangtan) Gowa, Sulawesi Selatan
}

\begin{abstract}
The partners in this community serviceactivityarethe Lantebung farmer group, Pakatto Village, Bontomarannu District in Gowa Regency. Their problems are 1). lack of knowledge, attitudes and skills of cattle farmers towards utilization of cattle feces as an alternative fuel with sago flour adhesives; 2) Cattle feces waste has not been used optimally becomes higher economic value product. The external target is cattle feces have a higher economic value after being processed into feces briquettes. The implementation and extension design includes the determination of material, methods, techniques, media, targets, implementations and evaluations. The result achieved are: 1) Improved partners knowledge, attitudes and skills to use of cattle feces into briquettes with sago flour adhesives. 2) Increased the economic value of cattle feces.
\end{abstract}

Keywords: briquettes, cattle feces, sago flour

\section{PENDAhUluAN}

Sapi merupakan usaha sampingan sebagian petani di desa Lantebung. Populasi ternak sapi di desa Pakatto Kecamatan Bontomarannu Kabupaten Gowa adalah 1.250 ekor. Jumlah kotoran yang dihasilkan oleh ternak sapi per ekor per hari ratarata adalah $10 \mathrm{~kg}$ (Nurdin, 2013). Jadi dari populasi sapi yang ada di Desa Pakatto yakni 1.250 ekor dapat diperoleh feses sebanyak 12.500 $\mathrm{kg} /$ hari. Salah satu pemanfaatan biomassa dari feses sapi yaitu dapat diolah dalam bentuk briket sebagai bahan bakar pengganti bahan bakar minyak (BBM).

Kegiatan Pengabdian kepada Masyarakat (PkM) dilaksanakan di Kelompoktani (Poktan) Lantebung beralamat di Desa Pakatto, Kecamatan Bontomarannu, Kabupaten Gowa. Pemilihan Poktan Lantebung secara purposive sampling yakni satuan sampel yang dipilih berdasarkan pertimbangan tertentu dengan tujuan untuk memperoleh satuan sampel yang memiliki karakteristik yang dikehendaki yaitu kelompoktani yang seluruh anggotanya memiliki ternak sapi. Anggota Poktan Lantebung sebanyak 20 orang dengan karakteristik anggota Poktan berdasarkan umur adalah 17-23 tahun sebanyak 2 orang (10\%), 24-30 tahun sebanyak 2 orang (10\%), 31-37 tahun sebanyak 5 orang (25\%), 38-44 tahun sebanyak 5 orang (25\%) dan $\geq 45$ tahun sebanyak 6 orang $(30 \%)$. Karakteristik anggota poktan berdasarkan pendidikan $65 \%$ lulus SLTA (13 orang), 25\% lulus SLTP (5 orang) dan $10 \%$ lulus SD (2 orang). Kepemilikan lahan bervariasi $0,25 \mathrm{Ha}$ sampai dengan $1 \mathrm{Ha}$, dengan jumlah sapi yang dipelihara anggota Poktan 30 ekor dengan rincian 10 anggota masingmasing memiliki 1 ekor dan 10 anggota masingmasing memiliki 2 ekor sapi.

Sistem pemeliharaan sapi di Poktan Lantebung umumnya dipelihara secara semi intensif, pagi digembala dan diikat di lahan kemudian malam dibawa kembali ke rumah. Kondisi ini menyebabkan feses sapi tidak optimal terkumpul selama pemeliharaan. Feses sapi umumnya yang terkumpul langsung dimanfaatkan untuk pupuk tanaman baik di kebun maupun sawah, bahkan ada sebagian peternak yang membuang begitu saja feses sapinya. Peternak berdasarkan survei awal juga tidak memiliki kemampuan mengolah feses tersebut menjadi produk yang meningkat nilai ekonominya.

Feses sapi disamping dijadikan pupuk organik, juga dapat ditingkatkan nilai ekonominya dengan 
mengolah menjadi briket untuk bahan bakar. Sarjono \& Ridlo (2013), bahwa nilai karakteristik dari tiap-tiap perlakuan komposisi briket kotoran sapi berbeda, seiring dengan meningkatnya persentase perekat tapioka maka kadar air dalam briket semakin bertambah sehingga nilai kalor semakin rendah. Nilai kalor berpengaruh terhadap laju pembakaran. Semakin tinggi nilai kalor pada briket, semakin tinggi pula laju pembakaran pada briket. Hasil kajian oleh Patontongan (2017), feses sapi dapat dijadikan briket dengan bahan perekat tepung sagu. Beberapa permasalahan yang dihadapi oleh anggota Poktan Lantebung adalah anggota kelompok memiliki pengetahuan, sikap dan keterampilan yang rendah dalam meningkatkan nilai ekonomi feses sapi menjadi produk yang bernilai ekonomi lebih tinggi. Salahsatu produk pengolahan feses untuk meningkatkan ekonomi adalah briket feses dengan perekat tepung sagu.

\section{METODE PELAKSANAAN}

Metode yang digunakan untuk meningkatkan pengetahuan, sikap dan keterampilan peternak di Poktan Lantebung meliputi persiapan (penetapan materi, metode, teknik, media, dan sasaran), pelaksanaan dan evaluasi.

\section{A. Persiapan Penyuluhan}

Materi yang disampaikan dalam penyuluhan ini adalah materi penyuluhan briket feses sapi tepung sagu sebagai bahan bakar alternatif. Metode yang digunakan adalah metode pendekatan perorangan dan metode pendekatan kelompok. Teknik penyuluhan yang digunakan adalah diskusi dan demonstrasi cara dengan tujuan agar proses adopsi lebih maksimal. Media penyuluhan yang digunakan adalah folder dan benda sesungguhnya agar sasaran lebih yakin dengan teknologi tersebut. Sasaran penyuluhan adalah petani/peternak sapi yang ada di Desa Pakatto, adapun sebagai responden adalah anggota Poktan Lantebung.

\section{B. Pelaksanaan Penyuluhan}

Penyuluhan dilaksanakan di rumah ketua kelompok tani Lantebung, Desa Pakatto, Kecamatan Bontomarannu, Kabupaten Gowa.
Materi penyuluhan yaitu Briket Feses Sapi Tepung Sagu Sebagai Bahan Bakar Alternatif. Peserta penyuluhan adalah petani/peternak sapi berjumlah 20 orang.

\section{Evaluasi Penyuluhan}

Tujuan dilakukannya evaluasi adalah untuk mengetahui apakah petani/peternak sapi dapat membuat briket dari feses sapi. Evaluasi terdiri dari evaluasi awal dan evaluasi akhir. Populasi pada evaluasi ini adalah petani/peternak sapi yang ada di Desa Pakatto Kecamatan Bontomarannu Kabupaten Gowa. Ukuran sampel atau jumlah sampel ditentukan dengan menggunakan teknik penarikan sampel Purposive Sampling (sampel pertimbangan) yakni satuan sampel yang dipilih berdasarkan pertimbangan tertentu dengan tujuan untuk memperoleh satuan sampel yang memiliki karakteristik yang dikehendaki yaitu kelompoktani yang seluruh anggotanya memiliki ternak sapi.

Instrumen evaluasi (kuesioner) yang digunakan terdiri dari 5 pertanyaan dan 3 kriteria untuk masing-masing aspek yang dinilai (pengetahuan, sikap dan keterampilan). Data hasil evaluasi direkap dan ditabulasi kemudian dianalisis menggunakan perhitungan uji statistik Dependen Samples $T$ Test membandingkan rata-ratanilai sebelum dan sesudah penyuluhan.

\section{HASIL DAN PEMBAHASAN}

\section{A. Respon Petani terhadap Materi}

Respon berasal dari kata response, yang berarti balasan atau tanggapan (reaction). Respon adalah istilah psikologi yang digunakan untuk menamakan reaksi terhadap rangsang yang diterima oleh panca indra. Hal yang menunjang dan melatar belakangi ukuran sebuah respon adalah sikap, persepsi dan partisipasi. Respon pada prosesnya didahului sikap seseorang karena sikap merupakan kecenderungan atau kesediaan seseorang untuk bertingkah laku jika menghadapi suatu rangsangan tertentu. Jadi, berbicara mengenai respon atau tidak respon terlepas dari pembahasan sikap. Respon juga diartikan sebagai suatu tingkah laku atau sikap yang berwujud baik sebelum pemahaman yang mendetail, penelitian, pengaruh atau penolak- 
an, suka atau tidak suka serta pemanfaatan pada suatu fenomena tertentu (Sobur, 2003).

Kehadiran petani pada pelaksanaan penyuluhan serta keterlibatannya langsung pada demonstrasi cara pembuatan briket membuktikan bahwa mereka merespon baik kajian materi Briket Feses Sapi Tepung Sagu Sebagai Bahan Bakar Alternatif.

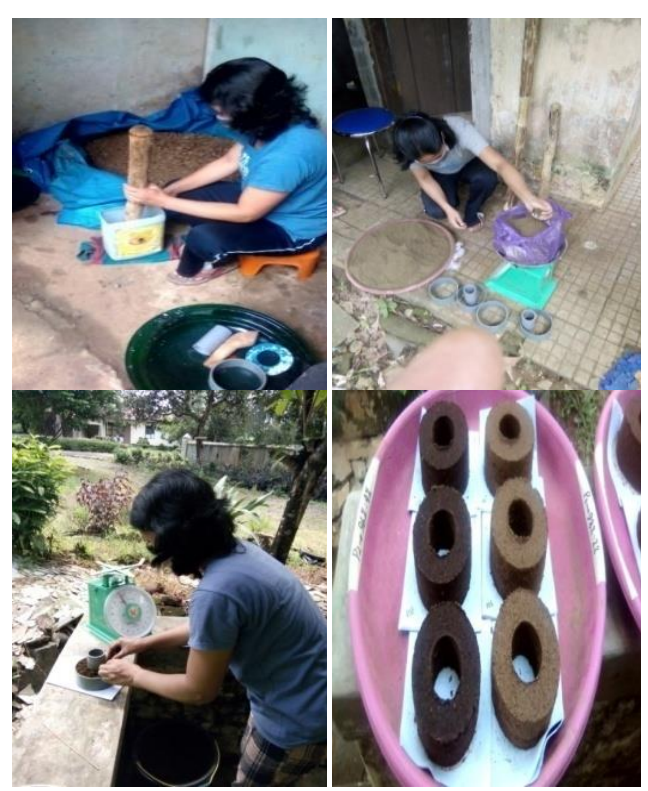

Gambar 1. Proses pembuatan briket feses sapi dengan bahan perekat tepung sagu

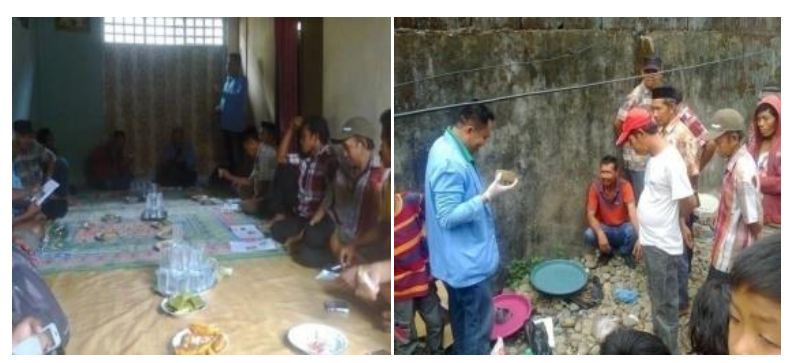

Gambar 2. Kegiatan pelaksanaan penyuluhan

\section{B. Evaluasi Penyuluhan Pertanian}

Evaluasi penyuluhan pertanian dilakukan untuk mengukur tingkat pengetahuan, sikap dan keterampilan peternak terhadap inovasi teknologi yang disampaikan melalui kegiatan penyuluhan pertanian dengan menggunakan alat ukur (kuesioner) yang terdiri dari 5 pertanyaan dan 3 kriteria untuk masing-masing aspek yang dinilai. Evaluasi penyuluhan pertanian yang dilakukan terdiri dari evaluasi awal dan evaluasi akhir.
Hasil evaluasi awal untuk masing-masing aspek yang dinilai yaitu pengetahuan $49,67 \%$, sikap $60,33 \%$ dan keterampilan 49,67\%. Sementara hasil evaluasi akhir untuk masing-masing aspek yaitu pengetahuan $81,33 \%$, sikap $93 \%$ dan keterampilan $75,67 \%$. Nilai perbedaan rata-rata dan selisih pasangan responden pada tingkat pengetahuan adalah $-4,75$, pada tingkat sikap $-4,9$ dan pada tingkat keterampilan $-3,9$.

Hasil evaluasi awal dan akhir tingkat pengetahuan, sikap dan keterampilan diuji menggunakan uji Dependen Sample T-Test untuk tingkat pengetahuan diketahui nilai signifikansinya $0,00<0,05$ artinya hasil evaluasi menunjukkan adanya perbedaan yang signifikan antara hasil evaluasi awal dan hasil evaluasi akhir. Demikian pula pada tingkat sikap diperoleh nilai signifikansi $0,00<0,05$ dan tingkat keterampilan dengan nilai signifikansi $0,004<0,05$.

\section{KESIMPULAN}

Hasil pelaksanaan kegiatan PkM dapat ditarik kesimpulan:

1. Petani mengalami peningkatan/perubahan sikap sebesar $32,67 \%$, pengetahuan $31,66 \%$ dan keterampilan $26 \%$.

2. Petani mampu meningkatkan nilai ekonomi feses sapi menjadi briket pengganti bahan bakar.

\section{DAFTAR PUSTAKA}

Nurdin, Ellyza (2013). Penerapan Teknologi Pembuatan Bioarang Dengan Memanfaatkan Limbah Kotoran Di Peternakan Sapi Potong Zelti Farm Lubuk Minturun Kodya Padang. Fak. Peternakan Universitas Andalas. Padang.

Patontongan, Sarti (2017). Briket Feses Sapi Tepung Sagu (Brifestagu) Sebagai Bahan Bakar Alternatif. Karya Ilmiah Penugasan Akhir (KIPA) Sekolah Tinggi Penyuluhan Pertanian (STPP) Gowa.

Sarjono, Muhammad Ridlo (2013). Studi Eksperimental Penggunaan Kotoran Sapi Sebagai Bahan Bakar Alternatif. Majalah Ilmiah STTR Cepu. ISSN 1693-7066 Nomor 16 Tahun 11 Januari-Juni 2013.

Sobur, Alex (2003). Psikologi Umum. Pustaka Setia. Bandung. 